\title{
Total-arterial, anaortic, off-pump coronary artery surgery: Why, when, and how
}

Michael P. Vallely, MBBS, PhD, FRACS, ${ }^{\mathrm{a}}$ Michael Seco, BMedSc, MBBS, PhD, ${ }^{\mathrm{b}}$ Fabio Ramponi, MD, FEBVS, and John D. Puskas, MD, FACS ${ }^{\mathrm{d}}$

Video clip is available online.

"We choose to go to the moon in this decade and do the other things. Not because they are easy, but because they are hard."

—John F. Kennedy.

WHY

Ischemic heart disease remains the leading cause of death worldwide. ${ }^{1}$ Coronary artery bypass grafting (CABG) has consistently been shown to be the best treatment for patients with complex left main and multivessel disease. ${ }^{2}$ However, coronary surgery for many surgeons, and many surgical units, remains a "commodity" item with little change in the procedure for more than 40 years. This is despite strong evidence for the use of more advanced techniques including multi- and total-arterial grafting, and off-pump techniques that avoid all aortic manipulation ("anaortic" surgery).

The most common technique of CABG remains a left internal thoracic artery (LITA) to the left anterior descending (LAD) artery, with reversed saphenous vein grafts (SVGs) to other targets, performed using cardiopulmonary bypass with aortic crossclamping and cardioplegic arrest. This remains a "good" procedure, with superior outcomes to percutaneous coronary intervention (PCI) for complex multivessel disease. ${ }^{2}$ The

\footnotetext{
From the a Division of Cardiac Surgery, The Ohio State University Wexner Medical Center, Columbus, Ohio; ' Department of Cardiothoracic Surgery, The Children's Hospital at Westmead, Sydney, Australia; ' Department of Cardiothoracic Surgery, Royal Adelaide Hospital, Adelaide, Australia; and ${ }^{\mathrm{d}}$ Department of Cardiovascular Surgery, Mount Sinai Morningside, New York.

Received for publication Aug 4, 2021; accepted for publication Sept 27, 2021; available ahead of print Oct 4, 2021.

Address for reprints: Michael P. Vallely, MBBS, PhD, FRACS, Division of Cardiac Surgery, The Ohio State University, Wexner Medical Center, N-805 Doan Hall, 410 West 10th Ave, Columbus, OH 43210 (E-mail: michael.vallely@osumc.edu). JTCVS Techniques 2021;10:140-8

2666-2507

Copyright (C 2021 The Author(s). Published by Elsevier Inc. on behalf of The American Association for Thoracic Surgery. This is an open access article under the CC BY-NC-ND license (http://creativecommons.org/licenses/by-nc-nd/4.0/). https://doi.org/10.1016/j.xjtc.2021.09.050
}

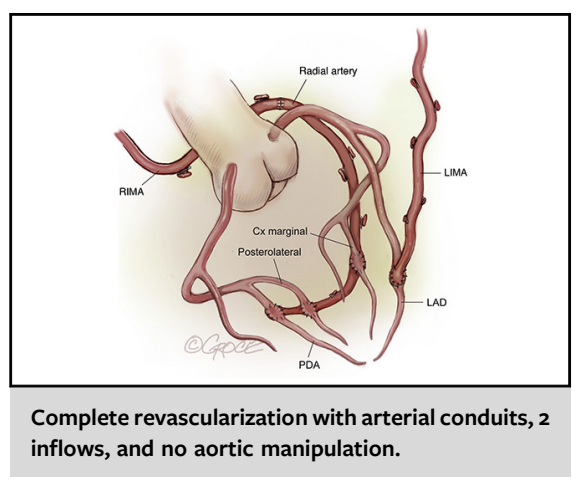

CENTRAL MESSAGE

Total-arterial, anaortic, off-pump

surgery with complete revascularization offers reduced neurologic injury by avoiding aortic manipulation and increased survival associated with arterial grafts.

See Commentaries on pages 149 and 151.

proven long-term patency rate and survival benefits of the LITA to LAD have been known for several decades now. However, it is not a "great" procedure since the long-term failure rates of SVGs have also been known for several decades. ${ }^{3,4}$ This contrasts with the robust data for the long-term benefits of the use of multi- and total-arterial grafting, including the use of the right internal thoracic artery (RITA) and the radial artery as a second or third conduit. ${ }^{5-11}$ SVGs have the added, and often overlooked, disadvantage of causing progression of native coronary artery disease that may preclude effective reintervention if the vein graft fails. ${ }^{12,13}$

Multiarterial and total-arterial grafting have also received significantly more attention recently. The publication of the RADIAL individual participant data meta-analysis demonstrated superior outcomes with the radial artery over SVG. ${ }^{5}$ The randomized ART trial has been more controversial. ${ }^{6}$ Although the intention-to-treat analysis demonstrated no difference between single versus bilateral internal thoracic artery (ITA) grafting, there was a significant crossover rate $(40 \%$ received a different therapy 
to one they were assigned) combined with the high use of radial artery in the single ITA group ( $22 \%$ of patients), which makes this difficult to interpret. The as-treated analysis on the other hand showed a significant advantage in patients who received multiarterial compared with single-arterial grafting ( $8 \%$ difference in absolute survival). Although this analysis is no longer randomized, more than 20 baseline characteristics were similar and provides a compelling argument. ${ }^{14}$ The significant benefit of the radial artery data has meant that the often-used argument of sternal wound complications from bilateral ITA harvesting is less relevant. Nonetheless, the ART trial also demonstrated that the use of a skeletonized harvest technique mitigates the risk of sternal wound issues from bilateral ITA harvesting anyway. ${ }^{15}$

The stroke rate, when compared with PCI, remains the Achilles' heel of $\mathrm{CABG}^{16}$ and is another often used argument to refer patients for PCI in circumstances where the complexity of their coronary artery disease would likely be best served with multivessel surgical revascularization. The main cause of perioperative stroke remains emboli, and the main source of emboli stems from the aortic manipulation associated with cannulation, "sandblasting" from the aortic cannula inflow jet, crossclamping, and proximal anastomoses that are inherent to the on-pump, arrested heart CABG technique. ${ }^{17}$ Perioperative and delayed stroke have been shown to have a highly significant impact on mortality, with a meta-regression analysis showing that minimizing aortic manipulation, rather than intrinsic patient characteristics, had a protective effect on neurologic outcomes. ${ }^{18}$

A network meta-analysis performed by our group in 2017 identified that stepwise reduction and ultimately elimination of aortic manipulation resulted in superior neurologic outcome (and also superior early mortality, renal failure, bleeding, atrial fibrillation, and shorter length of intensive care) (Figure 1). ${ }^{19}$ Anaortic off-pump CABG (OPCAB) decreased the risk of postoperative stroke by $-78 \%$ versus on-pump CABG (single or double clamp), $-66 \%$ versus OPCAB with partial occlusion clamping, and $-52 \%$ versus $\mathrm{OPCAB}$ with the Heartstring device. In a separate subgroup analysis, anaortic OPCAB decreased risk by $-81 \%$ versus double-clamp on-pump CABG, and $-77 \%$ versus single-clamp on-pump CABG. The 2018 European Society of Cardiology/European Association for Cardiothoracic Surgery Coronary Revascularization Guidelines (Figure 2) recommends minimization of aortic manipulation as a Class 1B indication and off-pump (preferably anaortic) in high-risk patients and those with calcified aortas. $^{2}$ Likewise, a recent Scientific Statement from the American Heart Association on the prevention of stroke after $\mathrm{CABG}$ has confirmed anaortic OPCAB as an essential technique for the reduction of stroke during CABG. $^{20}$
Total-arterial, anaortic, OPCAB therefore represents the culmination of advanced techniques based on the aforementioned evidence for conduit selection and reducing perioperative neurologic injury. It involves the use of single or bilateral ITA inflows, combined with the radial artery to manufacture composite grafts. Complete surgical revascularization is then accomplished using sequential grafting techniques off-pump, without manipulating the aorta. The procedure, until recently, has occupied a niche (even "fringe") position within the CABG community. However, more recently the outcomes of the technique and the principles behind the thesis that avoiding cerebral emboli and providing multiarterial revascularization provides better short and long-term outcomes have received more widespread attention.

The changes in treatment guidelines and scientific statements from these august bodies, confirming the benefits of these advanced techniques, have served to bring them into the mainstream as well. This raises some of the other, perhaps more compelling reasons for pursuing multiarterial and anaortic techniques. Patients and referrers also have access to this information and will eventually realize that not all $\mathrm{CABG}$ are the same. Adverse events may be scrutinized with more attention as to the conduct of the operation, the expertise and experience of the surgeon, and the specific techniques used. It behooves the specialty to embrace more advanced techniques and move toward a better $\mathrm{CABG}$ for all patients.

\section{WHEN}

One of the most frequently used arguments against OPCAB is the "technical issues and difficulty" of the procedure. This was certainly the observation made after the ROOBY trial. ${ }^{21}$ Interestingly, both sides of the OPCAB debate have held the ROOBY trial up as a beacon for their arguments. The CORONARY trial, on the other hand, demonstrated equivalent results with on-pump and OPCAB. ${ }^{22}$ The surgeons participating in the ROOBY trial were relatively inexperienced (including residents), whereas the CORONARY trial surgeons were all experienced surgeons, with a need to have performed more than 200 cases to be eligible. Other series of "experienced" OPCAB surgeons have still reported higher rates of incomplete revascularization and repeat revascularization, with negative effects on long-term outcomes. $^{23}$

Although the "technical difficulty" argument may have some validity, this should not be used as a reason for not pursuing techniques that have the dual advantage of long-term survival benefit through multiarterial grafting and significantly reduced intraoperative stroke. Nor does it mean that achieving patent anastomoses and complete revascularization in all patients is not possible, as demonstrated by the strategies described next. Two recent 


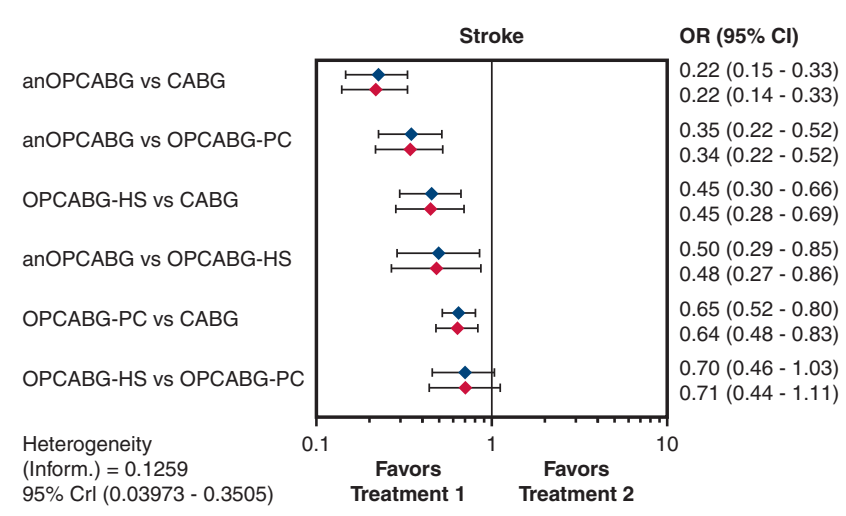

A

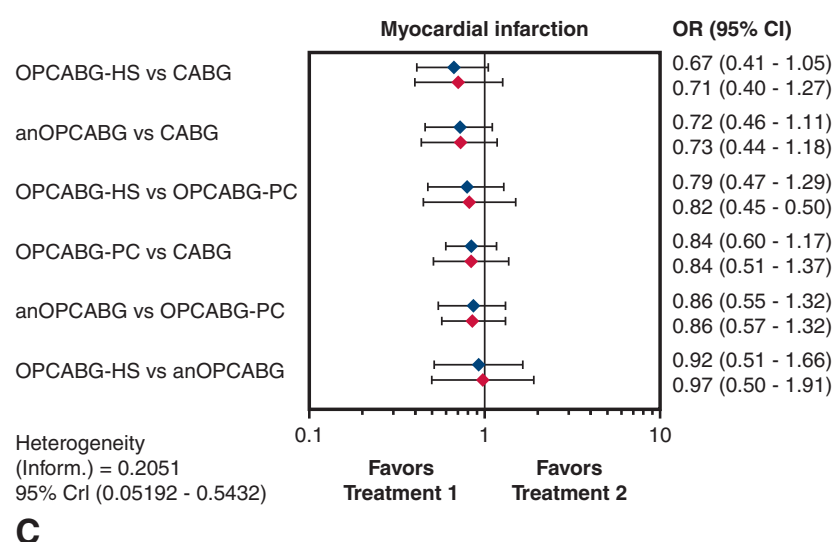

C

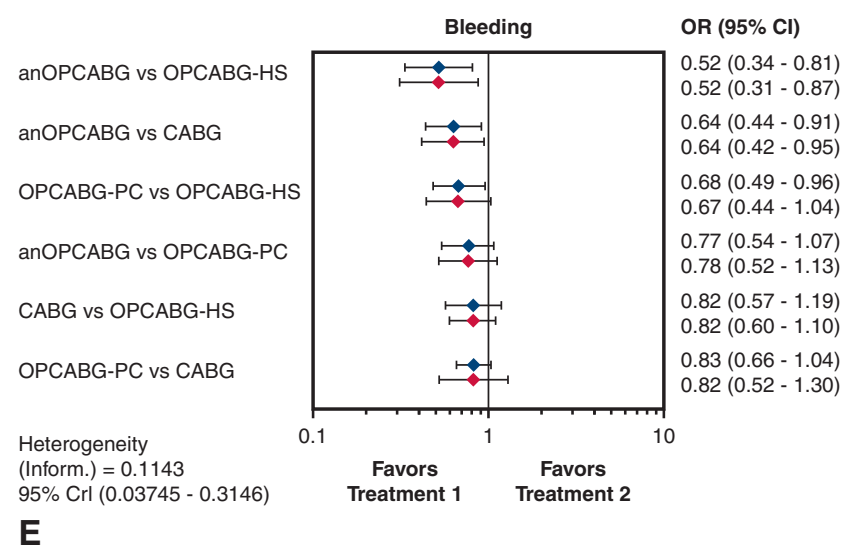

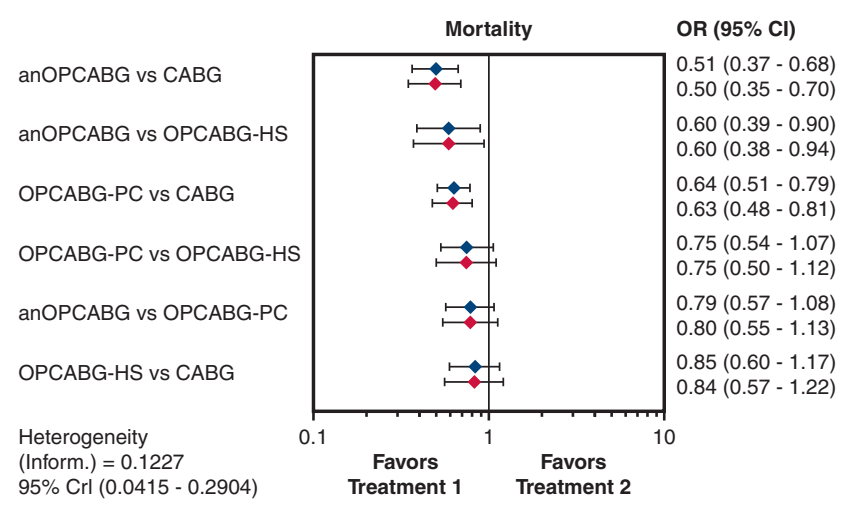

B

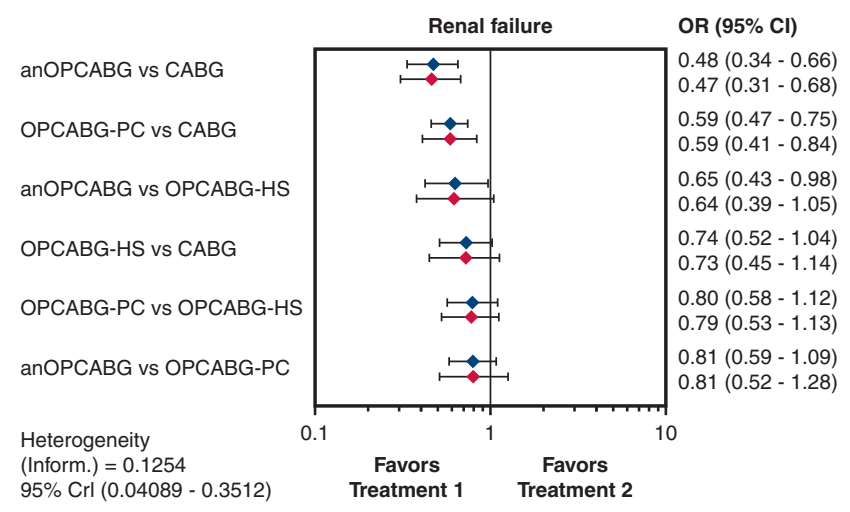

D

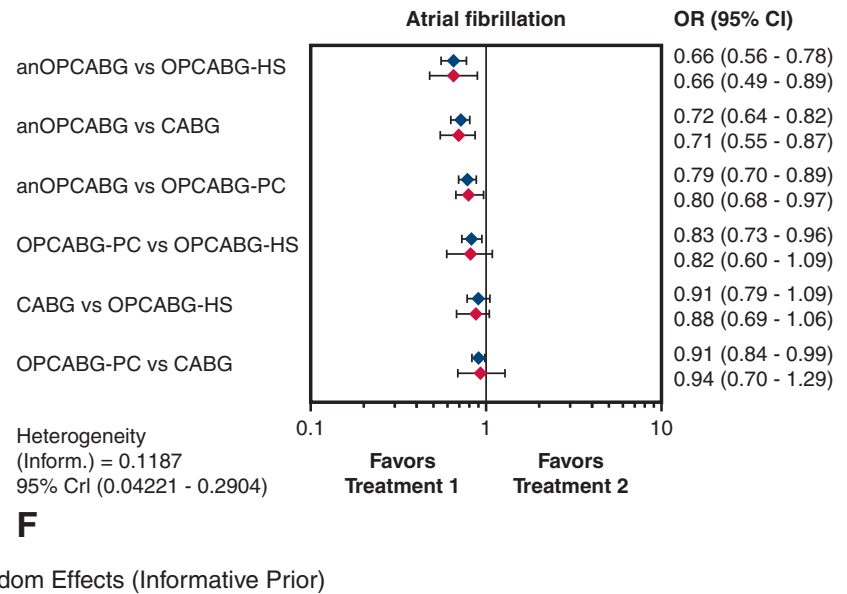

FIGURE 1. Forest plots of (A) stroke, (B) mortality, (C) myocardial infarction, (D) renal failure, (E) bleeding complications, and (F) atrial fibrillation after CABG with and without manipulation of the aorta. ${ }^{19} \mathrm{HS}$, Heartstring "clampless" proximal anastomosis device; PC, partial clamp. Reprinted with permission.

publications have outlined practical, stepwise approaches that enable individual surgeons and surgical programs to progress from the "basic" LITA/SVG on-pump CABG to these more advanced techniques, including total-arterial anaortic OPCAB (Figure 3). ${ }^{24,25}$ Units that have adopted these advanced techniques have shown progressive improvements in patient outcomes over time. ${ }^{26}$
Another philosophy of many surgeons is that OPCAB and anaortic OPCAB should be reserved for high-risk patients only. We would argue that anaortic OPCAB should be the intention to treat in all patients. The reasons for this are multiple: The evidence for reduced neurologic injury has been found in meta-analysis of all patients, ${ }^{19}$ and not only high-risk subgroups; the use of multi/total-arterial 


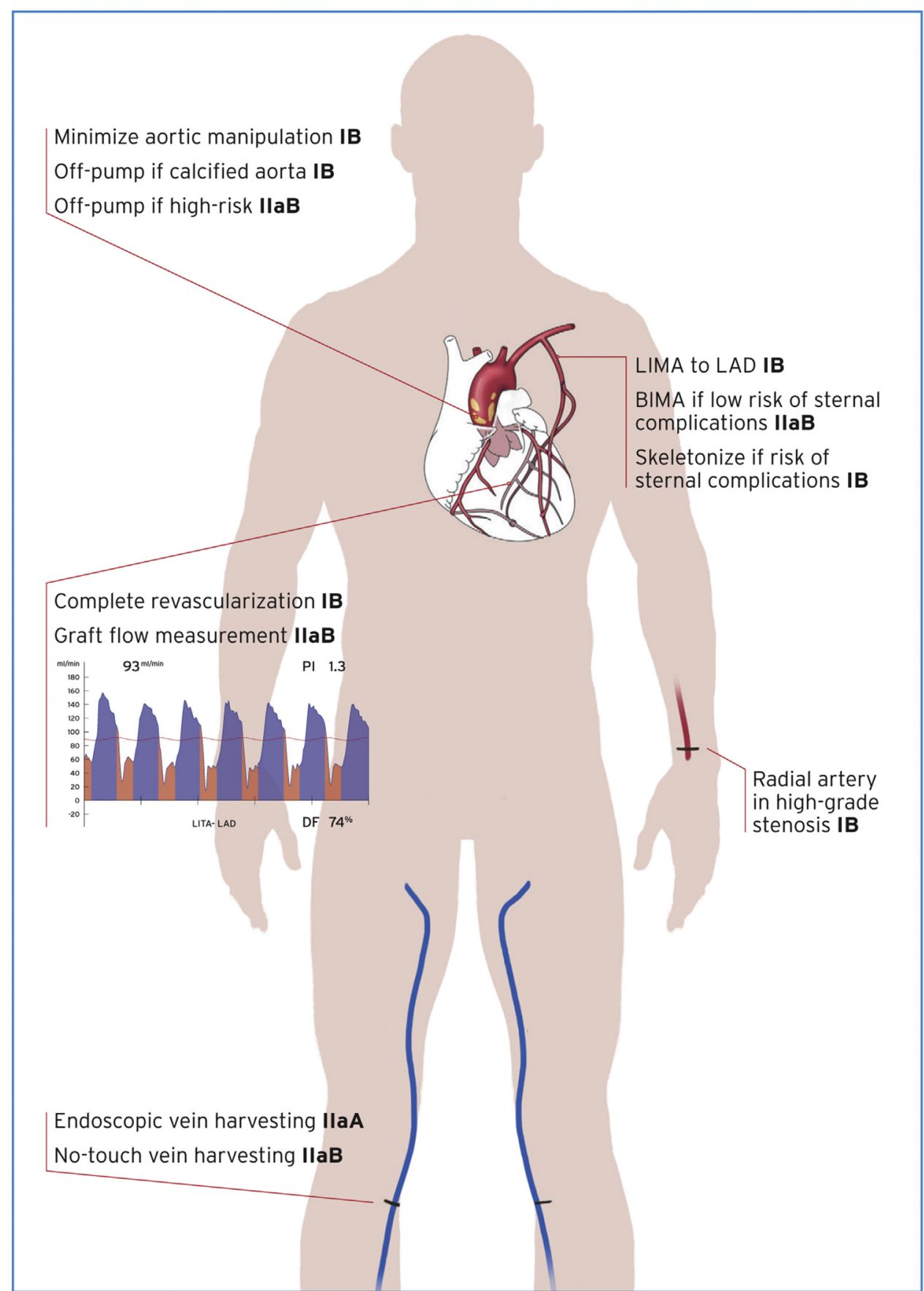

FIGURE 2. 2018 European Society of Cardiology/European Association for Cardiothoracic Surgery Coronary Revascularization Guideline recommendations for specific surgical techniques. ${ }^{2}$ Reprinted with permission.

grafts is inherent to the anaortic OPCAB technique, which is of benefit to all patients and in particular young, low-risk subgroups; and finally, it is imperative to be skilled at anaortic surgery for when a patient absolutely requires it (eg, porcelain aorta, grade V atheroma). As with many other pursuits in life, whether it be hitting a golf ball, writing poetry, or repairing mitral valves ${ }^{27}$ the more one does it, the better one becomes at it. This does not mean that all patients must have the procedure, just that one needs to justify why they are not performing it in each patient or under a given set of circumstances. This approach will have the 2-fold benefit of improved patient outcomes and 


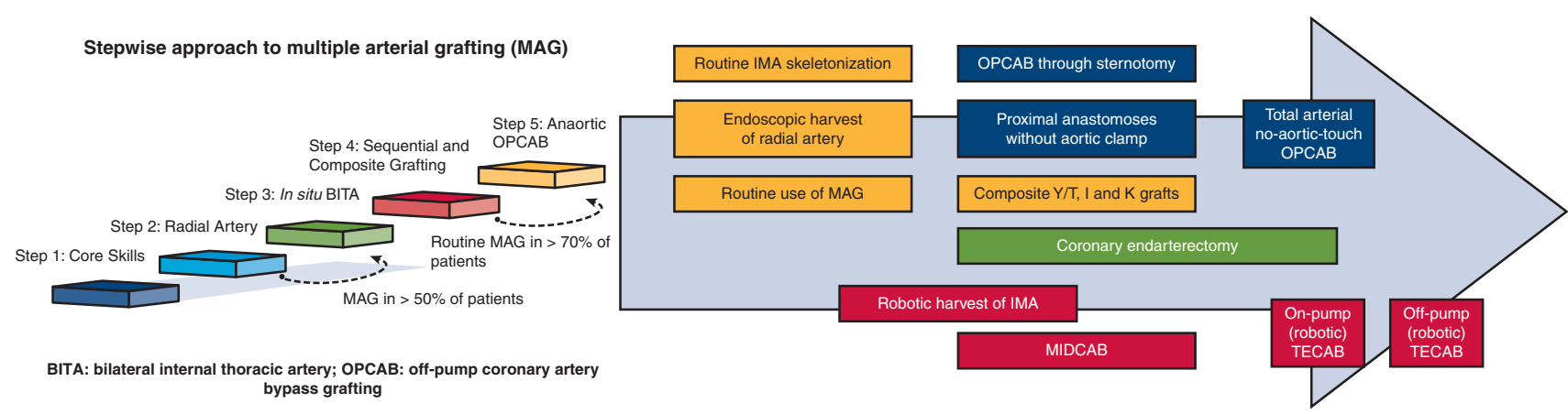

FIGURE 3. Stepwise approaches to developing advanced coronary surgery programs culminating in anaortic off-pump CABG. ${ }^{24,25}$ Reprinted with permission.

increased surgical expertise due to repetition and increased volume.

\section{HOW}

Our primary technique for performing anaortic multiarterial OPCAB is presented in the Video 1. A summary of main principles is included next. More detailed descriptions are also available in our previous publications focused on surgical techniques. ${ }^{28-33}$

Composite grafts based on inflow from one or both ITAs underpin anaortic OPCAB surgery. There have been many iterations of composite grafts described over the years. ${ }^{29,34,35}$ Our standard configuration for triple vessel coronary disease is an in situ skeletonized LITA-LAD and an in situ skeletonized RITA extended end-to-end with the radial artery and brought through the transverse sinus to revascularize the lateral and inferior wall vessels (Figure 4, A). This allows for all coronary targets to be adequately reached and complete revascularization achieved; separates the anterior wall blood supply from the rest of the heart, thus protecting the integrity of the LITA-LAD graft; and keeps grafts away from the midline anteriorly in case sternal reentry is required in the future.

In patients with triple vessel disease and high-grade lesions only, alternatives for complete revascularization include in situ LITA-LAD and LITA-Radial or LITA-RITA "T" graft to lateral and inferior walls (Figure 4, B). Studies have demonstrated excellent long-term outcomes with this approach. ${ }^{36,37}$ The advantage of the LITA-Radial composite graft is the ability to harvest both conduits simultaneously and reduce operating time, while the advantage of the LITA-RITA composite graft is the avoidance of a second incision and better size-matched conduits. In patients with left-sided coronary lesions only, the aforementioned " $T$ " grafts may be used or an in situ RITA-LAD and in situ LITA-lateral wall configuration is possible (Figure 4, C). In patients in whom a diagonal vessel requires grafting, although the vessel angle is not conducive to a sequential anastomosis using the LITA, a short segment of radial artery can be used as a "Y" graft (Figure 4,D). This can be performed in combination with an in situ RITA ( \pm extension with the remaining radial artery).

There are circumstances where it is not possible to use additional arterial conduits or it carries substantial risk to do so. Radial arteries may not be suitable due to dystrophic calcification or inadequate ulnar artery collaterization; the radial artery may have been used for access for coronary angiography; occasionally, a patient's occupation may preclude them (eg, guitar virtuoso); or a coronary vessel with an intermediate-grade lesion requires grafting. Use of the bilateral ITAs may also be considered unacceptably high risk in obese and poorly controlled diabetic patients. In these patients in whom both the radial artery and RITA are not suitable for use, there are 2 options for maintaining an anaortic technique. First, a short segment only $(3-4 \mathrm{~cm})$ of in situ RITA may be harvested and the vessel extended with a longer segment of SVG. This preserves the majority of the RITA blood flow to the sternum via intercostal vessels and provides some of the theoretical advantages of a second

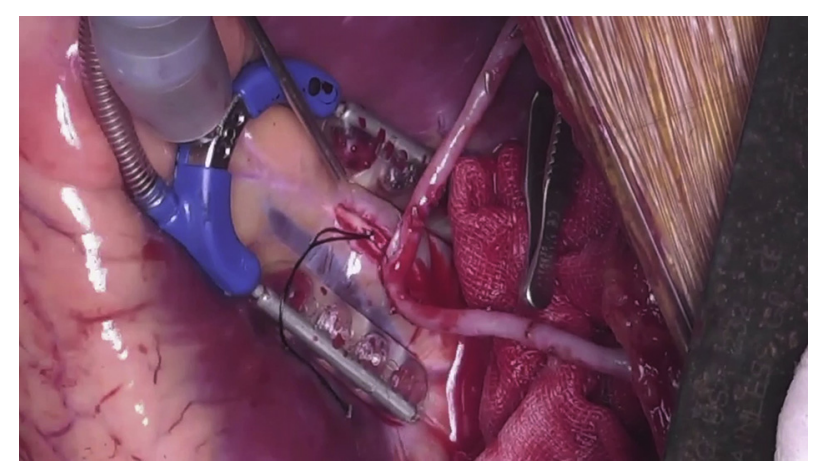

VIDEO 1. Total-arterial, anaortic, OPCAB technique. Components demonstrated: fully skeletonized ITA harvest, retrothymic tunnel formation, pericardial release incisions, RITA-Radial end-to-end extension anastomosis, pericardial "heart string" insertion, passing RITA-Radial extension graft through transverse sinus, high lateral wall sequential anastomosis, inferior wall anastomosis, anterior wall anastomosis, intracoronary shunt insertion, and transit-time flow measurement. Video available at: https://www.jtcvs. org/article/S2666-2507(21)00682-9/fulltext. 


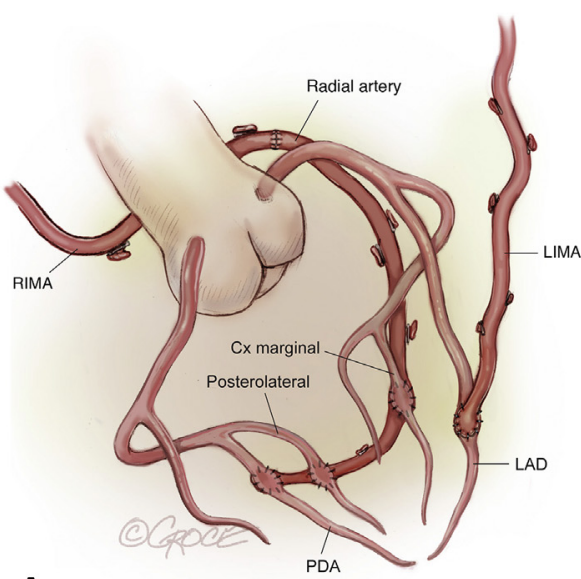

A

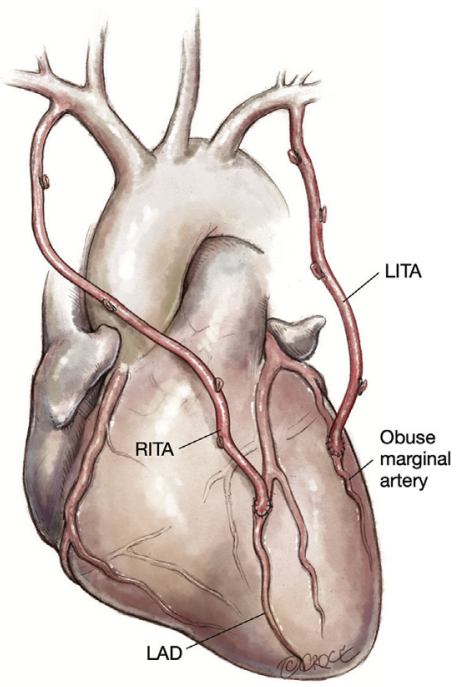

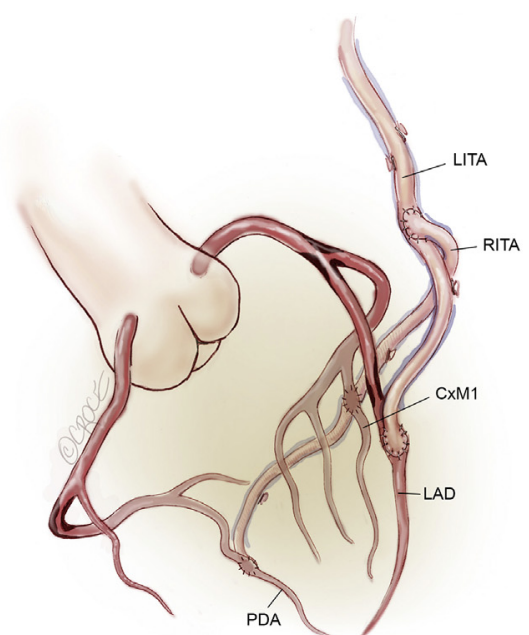

B

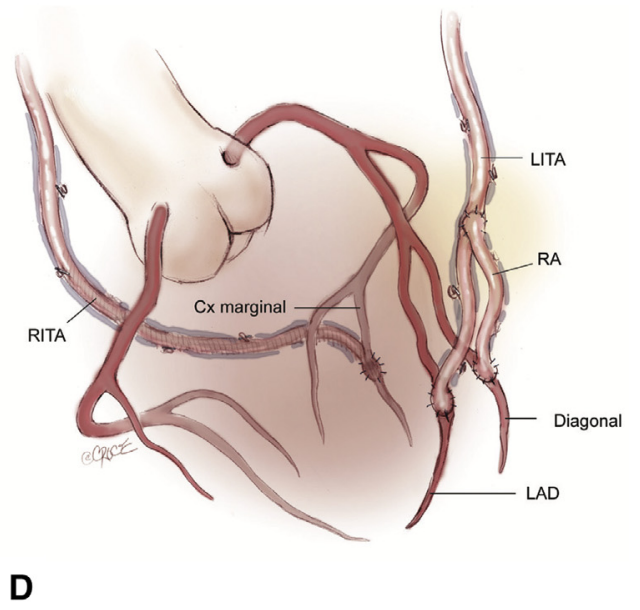

FIGURE 4. Grafting strategies to maintain an anaortic off-pump technique, using multiple-arterial conduits. A, In situ LITA-LAD and in situ RITA-radial extension-lateral/inferior walls. ${ }^{29} \mathrm{~B}$, In situ LITA-LAD and LITA-RITA (pictured) or LITA-radial "T" graft-lateral/inferior walls. ${ }^{34} \mathrm{C}$, In situ RITA-LAD and in situ LITA-lateral wall. ${ }^{35} \mathrm{D}$, In situ LITA-LAD, LITA-Radial "Y" graft-diagonal vessel, and RITA-lateral wall. ${ }^{34}$ Figures reprinted according to CC BY-NC-ND 4.0 license (https://creativecommons.org/licenses/by-nc-nd/4.0/).

in situ graft while avoiding the need for a proximal aorto-venous anastomosis. Alternatively, a LITA-SVG "T" graft also can be used.

All patients must be worked up systematically and have all standard testing as for other open procedures. A carotid and subclavian duplex ultrasound is performed to screen patients, and if there is significant disease, a computed tomography aortogram with arch vessel run-off is performed. If there is significant carotid disease found, then combined carotid endarterectomy is considered. If there is proximal subclavian artery narrowing, then preoperative stenting may be required to enable the ITA to be used as an in situ graft. A noncontrast computed tomography of the chest is also performed routinely. This allows for risk stratification and the ability for other surgeons to refer patients to the anaortic team if aortic atheroma or calcium is detected. It also allows planning around cannulation if a patient requires cardiopulmonary bypass. An Allen's test and radial artery ultrasound are performed to assess usability.

The harvesting of ITAs must be done in a skeletonized fashion. This technique has been shown to be superior to pedicled ITA harvesting for the preservation of the sternal blood supply and the reduction of deep sternal wound infections. $^{15}$ There are also technical benefits, as skeletonized grafts are longer than pedicled grafts and the lack of extraneous tissue makes them easier to pass through the retro-thymic tunnels and the transverse sinus, and to perform sequential grafting.

After the ITAs have been harvested and before opening the pericardium, bilateral retrothymic tunnels are fashioned, and the ITAs are brought through their respective side. The pericardium is then opened longitudinally in an 

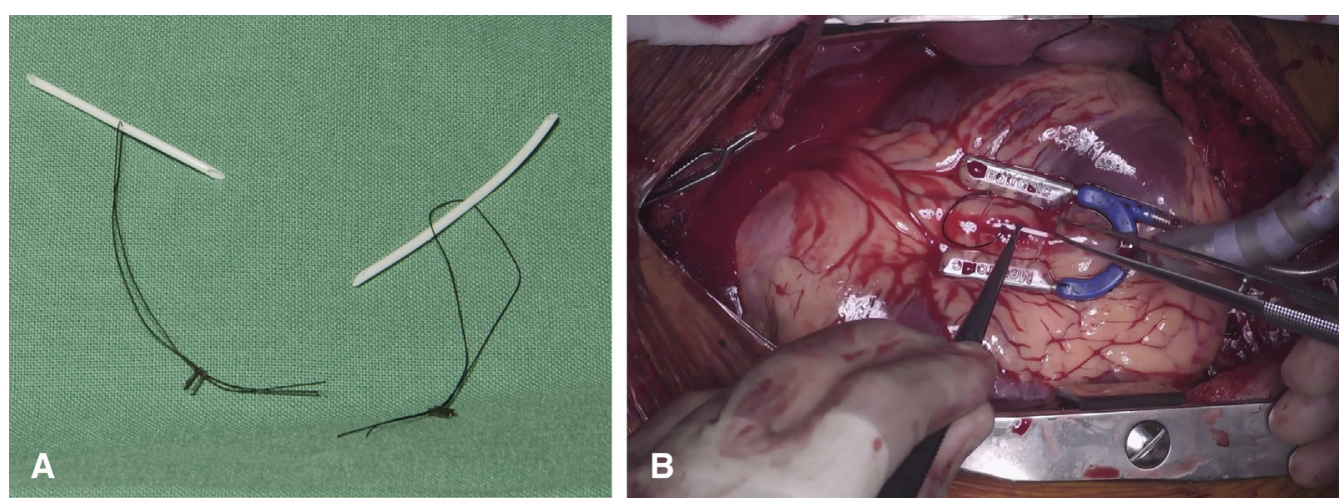

FIGURE 5. Intracoronary silastic shunts: preparation (A) and insertion (B). ${ }^{28}$ Reprinted according to CC BY 4.0 license (https://creativecommons.org/ licenses/by/4.0/).

inverted " $T$ " fashion with the left-sided pericardium hitched up behind the sternal retractor. Right-sided pericardial release incisions are then performed inferiorly at the diaphragm, and superiorly at the radial artery/superior vena cava junction. This allows the surgeon to rotate the heart across to the right on the "caval axis," which maintains venous return and allows easy access to the lateral wall for grafting.

Intracoronary shunts are used for all anastomoses. We prefer using homemade shunts that are made from the silastic loops used to occlude vessels intraoperatively (Figure 5). The shunts are soft and atraumatic, easy to insert and remove, and easy to pull a $7 / 0$ suture from if they are inadvertently caught during an anastomosis. There are 3 main reasons for using an intracoronary shunt: (1) They prevent technical problems during the anastomosis, including collecting the back-wall with a suture; (2) they provide a relatively bloodless field for performing the anastomosis; and (3) they provide distal perfusion to the myocardium during the anastomosis. Other reasons for using intracoronary shunts include the avoidance of crush injuries of the native coronary artery caused by bull-dog clamps or silastic tapes that are applied to control the coronary artery, and they also prevent injury to underlying structures, such as the right ventricle or coronary veins from silastic tape application.

The order of grafting is the high-lateral wall first, followed by low-lateral wall, inferior wall, and anterior wall. This allows more flexibility in positioning the heart while grafting the lateral wall, preventing traction injury to the LITA, and allowing for sequential revascularization of the heart. However, if the patient has critical left main or LAD disease then the LAD should be grafted first, and LITA is kept slightly longer to increase the flexibility in positioning the heart when grafting the other territories.

It is also imperative that the technical aspects of the grafts are optimized and then interrogated. The fashioning of the retrothymic tunnels and the pericardial release incisions are important to facilitate a straight and unimpeded lie for the grafts. Familiarity and expertise with sequential diamond/side-to-side anastomoses on a still heart are necessary before embarking on sequential grafting on a beating heart. The distances between grafts need to be optimized to prevent tension if the graft is too short or kinking if the graft is too long. When the grafts are completed, the flow should be interrogated and documented using transit-time flow measurement and epicoronary ultrasound of each anastomosis. ${ }^{2}$ If there are technical issues or inadequate flow parameters, then any anastomoses should be revised. Detailed articles on transit-time flow measurement are available. ${ }^{38,39}$

Last, hemodynamic instability during grafting can be encountered, particularly in patients with recent ischemic instability, critical left main disease, large hearts, and impaired preoperative ventricular function. It is ideal to have a primed cardiopulmonary bypass machine in the operating room in these cases. If conversion is required, then it is still possible to avoid crossclamping the aorta and to minimize manipulation. The ascending aorta is assessed with transesophageal echocardiography and epiaortic ultrasound for a suitable cannulation site. If there is significant atheroma, then the right axillary artery can be used instead. The heart is left beating, and the conduit configuration and anastomoses are performed in the same manner as described. If the left ventricle distends during positioning, then a vent is placed in the right superior pulmonary vein.

\section{CONCLUSIONS}

Coronary artery surgery remains a "commodity" procedure for many surgeons, with little subspecialization among surgeons or surgical centers. CABG with a LITA to LAD and SVGs to other targets has been the mainstay of surgical revascularization for the best part of 5 decades now. This is despite improved outcomes from the use of additional arterial grafts, including the RITA and radial 
artery. Likewise, avoiding aortic manipulation through "anaortic" OPCAB techniques has been shown to significantly reduce perioperative neurologic injury.

The simple addition of a radial artery graft to the second most important target is a good place for surgeons to start. Adding sequential grafting and composite grafting to the armamentarium can assist with familiarization with the techniques before taking more advanced steps. The identification of surgeons with talent and interest in advanced coronary surgery is another important step in the development of a program.

Multi/total-arterial grafting is more difficult than using vein grafts, and performing anaortic OPCAB is more difficult than performing surgery on bypass with an arrested heart. However, this is not a great excuse for the profession not to pursue the techniques in the interest of patient outcomes. Stepwise approaches to surgeon and unit development have been published, and there is a groundswell of support for coronary surgery to become a subspecialty of adult cardiac surgery.

\section{Conflict of Interest Statement}

M.P.V. is a member of the Medtronic North American Surgical Strategic Advisory Board. J.D.P. receives royalty payments from coronary surgical instruments manufactured by Scanlan and consultant fees for OPCAB training from Medtronic. This did not influence the writing of this manuscript. Written informed consent for the publication of operative images and video was obtained from patients. All other authors declared no conflicts of interest.

The Journal policy requires editors and reviewers to disclose conflicts of interest and to decline handling or reviewing manuscripts for which they may have a conflict of interest. The editors and reviewers of this article have no conflicts of interest.

\section{References}

1. World Health Organization. The top 10 causes of death. https://www.who.int/ news-room/fact-sheets/detail/the-top-10-causes-of-death. Accessed August 4, 2021.

2. Neumann FJ, Sousa-Uva M, Ahlsson A, Alfonso F, Banning AP, Benedetto U, et al. 2018 ESC/EACTS guidelines on myocardial revascularization. Eur Heart J. 2019;40:87-165.

3. Caliskan E, de Souza DR, Böning A, Liakopoulos OJ, Choi YH, Pepper J, et al. Saphenous vein grafts in contemporary coronary artery bypass graft surgery. Nat Rev Cardiol. 2020;17:155-69.

4. Royse A, Pawanis Z, Canty D, Ou-Young J, Eccleston D, Ajani A, et al. The effect on survival from the use of a saphenous vein graft during coronary bypass surgery: a large cohort study. Eur J Cardiothorac Surg. 2018;54:1093-100.

5. Gaudino M, Benedetto U, Fremes S, Biondi-Zoccai G, Sedrakyan A, Puskas JD, et al. Radial-artery or saphenous-vein grafts in coronary-artery bypass surgery. $N$ Engl J Med. 2018;378:2069-77.

6. Taggart DP, Benedetto U, Gerry S, Altman DG, Gray AM, Lees B, et al. Bilateral versus single internal-thoracic-artery grafts at 10 years. N Engl J Med. 2019;380: 437-46.

7. Gaudino M, Bakaeen FG, Benedetto U, Di Franco A, Fremes S, Glineur D, et al. Arterial grafts for coronary bypass: a critical review after the publication of aRT and RADIAL. Circulation. 2019;140:1273-84.
8. Gaudino M, Benedetto U, Fremes S, Ballman K, Biondi-Zoccai G, Sedrakyan A, et al. Association of radial artery graft vs saphenous vein graft with long-term cardiovascular outcomes among patients undergoing coronary artery bypass grafting: a systematic review and meta-analysis. JAMA. 2020;324:179-87.

9. Gaudino M, Lorusso R, Rahouma M, Abouarab A, Tam DY, Spadaccio C, et al. Radial artery versus right internal thoracic artery versus saphenous vein as the second conduit for coronary artery bypass surgery: a network meta-analysis of clinical outcomes. J Am Heart Assoc. 2019;8:e010839.

10. Rocha RV, Tam DY, Karkhanis R, Wang X, Austin PC, Ko DT, et al. Long-term outcomes associated with total arterial revascularization vs non-total arterial revascularization. JAMA Cardiol. 2020;5:507-14.

11. Gaudino M, Puskas JD, Di Franco A, Ohmes LB, Iannaccone M, Barbero U, et al Three arterial grafts improve late survival: a meta-analysis of propensitymatched studies. Circulation. 2017;135:1036-44.

12. Dimitrova KR, Hoffman DM, Geller CM, Dincheva G, Ko W, Tranbaugh RF Arterial grafts protect the native coronary vessels from atherosclerotic disease progression. Ann Thorac Surg. 2012;94:475-81.

13. Jabagi H, Chong AY, So D, Glineur D, Rubens FD. Native coronary disease progression post coronary artery bypass grafting. Cardiovasc Revasc Med. 2020;21:295-302.

14. Taggart DP. Implications of the 10-year outcomes of the Arterial Revascularization Trial (ART) for multiple arterial grafts during coronary artery bypass graft. Eur J Cardiothorac Surg. 2019;56:427-8.

15. Benedetto U, Altman DG, Gerry S, Gray A, Lees B, Pawlaczyk R, et al. Pedicled and skeletonized single and bilateral internal thoracic artery grafts and the incidence of sternal wound complications: Insights from the Arterial Revascularization Trial. J Thorac Cardiovasc Surg. 2016;152:270-6.

16. Head SJ, Milojevic M, Daemen J, Ahn JM, Boersma E, Christiansen EH, et al Stroke rates following surgical versus percutaneous coronary revascularization. J Am Coll Cardiol. 2018;72:386-98.

17. Ramponi F, Seco M, Brereton RJL, Gaudino MFL, Puskas JD, Calafiore AM et al. Toward stroke-free coronary surgery: the role of the anaortic off-pump bypass technique. J Card Surg. 2021;36:1499-510.

18. Gaudino M, Rahouma M, Di Mauro M, Yanagawa B, Abouarab A, Demetres M, et al. Early versus delayed stroke after cardiac surgery: a systematic review and meta-analysis. J Am Heart Assoc. 2019;8:e012447.

19. Zhao DF, Edelman JJ, Seco M, Bannon PG, Wilson MK, Byrom MJ, et al. Coronary artery bypass grafting with and without manipulation of the ascending aorta: a network meta-analysis. J Am Coll Cardiol. 2017;69:924-36.

20. Gaudino M, Benesch C, Bakaeen F, DeAnda A, Fremes SE, Glance L, et al. Considerations for reduction of risk of perioperative stroke in adult patients undergoing cardiac and thoracic aortic operations: a Scientific Statement from the American Heart Association. Circulation. 2020;142:e193-209.

21. Shroyer AL, Hattler B, Wagner TH, Collins JF, Baltz JH, Quin JA, et al. Five-year outcomes after on-pump and off-pump coronary-artery bypass. N Engl J Med 2017;377:623-32.

22. Lamy A, Devereaux PJ, Prabhakaran D, Taggart DP, Hu S, Straka Z, et al. Fiveyear outcomes after off-pump or on-pump coronary-artery bypass grafting. $N$ Engl J Med. 2016;375:2359-68.

23. Chikwe J, Lee T, Itagaki S, Adams DH, Egorova NN. Long-term outcomes after off-pump versus on-pump coronary artery bypass grafting by experienced surgeons. J Am Coll Cardiol. 2018;72:1478-86.

24. Gaudino MFL, Sandner S, Bonalumi G, Lawton JS, Fremes SE, Coronary Task Force of the European Association for Cardio-Thoracic Surgery. How to build a multi-arterial coronary artery bypass programme: a stepwise approach. Eur $J$ Cardiothorac Surg. 2020;58:1111-7.

25. Rosati CM, Torregrossa G, Balkhy HH, Puskas JD. Dedicated training in advanced coronary surgery: need and opportunity. [editorial]. J Thorac Cardiovasc Surg. 2021;161:2130-4.

26. Albert A, Ennker J, Hegazy Y, Ullrich S, Petrov G, Akhyari P, et al. Implementation of the aortic no-touch technique to reduce stroke after off-pump coronary surgery. J Thorac Cardiovasc Surg. 2018;156:544-54.e4.

27. Badhwar V, Vemulapalli S, Mack MA, Gillinov AM, Chikwe J, Dearani JA, et al Volume-outcome association of mitral valve surgery in the United States. JAMA Cardiol. 2020;5:1092-101.

28. Seco M, Ramponi F, Brereton RJL, Bigelow GA, Ganapathi AM, Vallely MP Anaortic, off-pump coronary artery bypass using multiple arterial grafts: surgica technique. Vessel Plus. 2021;5:18. https://doi.org/10.20517/2574-1209.2020.100.

29. Ramponi F, Seco M, Edelman JJB, Brereton RJL, Wilson MK, Vallely MP, et al. Dual inflow, total-arterial, anaortic, off-pump coronary artery bypass grafting: how to do it. Ann Cardiothorac Surg. 2018;7:552-60. 
30. Ramponi F, Seco M, Edelman JJB, Brereton RJL, Wilson MK, Vallely MP. Total-arterial, anaortic, off-pump coronary artery bypass grafting - surgical technique. In: Gaudino M, ed. Technical Aspects of Modern Coronary Artery Bypass Surgery. Cambridge, MA: Academic Press; 2020:378.

31. Seco M, Edelman JJB, Ramponi F, Wilson MK, Vallely MP. Anaortic, off-pump, total-arterial coronary artery bypass grafting surgery. In: Kofidis T, ed. Minimally Invasive Cardiac Surgery. Boca Raton, FL: CRC Press; 2021:496.

32. Amabile A, Torregrossa G, Williams E, Puskas J. Mastering Off-pump, total arterial coronary artery bypass grafting: a step-by-step approach. Multimed Man Cardiothorac Surg. 2020;2020:309-22.

33. Yanagawa B, Puskas JD. Off-pump coronary artery bypass grafting. Oper Tech Thorac Cardiovasc Surg. 2016;21:2-19.

34. Buxton BF, Hayward PA. The art of arterial revascularization-total arterial revascularization in patients with triple vessel coronary artery disease. Ann Cardiothorac Surg. 2013;2:543-51.

35. Taggart DP. How I deploy arterial grafts. Ann Cardiothorac Surg. 2018;7:690-7.
36. Royse AG, Bellomo R, Royse CF, Clarke-Errey S, Boggett S, Kelly T, et al. Radial artery vs bilateral mammary composite y coronary artery grafting: 15year outcomes. Ann Thorac Surg. 2021;111:1945-53.

37. Royse AG, Brennan AP, Ou-Young J, Pawanis Z, Canty DJ, Royse CF. 21-Year survival of left internal mammary artery-radial artery-y graft. J Am Coll Cardiol. 2018;72:1332-40.

38. Brereton RJL. Transit time flow measurement in composite arterial revascularisation. [editorial]. Ann Cardiothorac Surg. 2018;7:710.

39. Amin S, Pinho-Gomes AC, Taggart DP. Relationship of intraoperative transit time flowmetry findings to angiographic graft patency at follow-up. Ann Thorac Surg. 2016;101:1996-2006.

Key Words: anaortic, aorta no-touch, arterial graft, coronary bypass, internal thoracic artery, neurologic injury, off-pump, radial artery, stroke 